\title{
Diversity and Equity Issues in Design: Course Creation as Impetus for Compassionate and Inclusive Design
}

KIWANA T. MCCLUNG

The University of Louisiana at Lafayette

Diversity and inclusion initiatives have been a part of national conversations among architecture organizations for quite some time now. With the AIA demonstrating their commitment to these issues through their various equity, diversity, and inclusions initiatives, NOMA's[2] continuous avocation for the licensure of minorities and women, and numerous other organizations [4] publishing the demographics concerning individuals on the path to licensure, there is no shortage of professionals actively working towards improving the numbers. The issue is concurrently addressed through schools' curriculums, per NAAB's[3] coverage of diversity and equity in school accreditation requirements, yet it is unclear whether these schools specifically address how architects may contribute or neglect these issues historically, intentionally or unintentionally. A new course was developed for architecture students addressing diversity and equity as a retrospective to inform future design decisions, with the ultimate goal of inclusivity and compassion. The course calls for the examination of the built environment through the lens of physical, social and economic access, public health, safety and welfare, briefly touching on the architect's role in public policy and personal versus professional ethics. The goal of the course is to address historical and current spatial deficits, as well as highlighting current trends and statistics that may directly affect the profession. As another approach for advancing diversity, equity, and inclusion, the course closes the loop on the diversity initiatives of the profession.

1. The American Institute of Architects has for many years been "actively engaged in furthering and supporting multiple initiatives and goals such as the Equity in Architecture Commission, K-12 strategies, Women Leadership and Multicultural Summits that value EDI for people of all backgrounds." https://www.aia.org/ resources/24301-equity-diversity-and-inclusion

2. The National Organization of Minority Architects employs the mission to "champion diversity within the design professions by promoting the excellence, community engagement, and professional development of its members." http:// www.noma.net/article/45/organization/about

3. The National Architectural Accreditation Board's Mission is the development and maintenance of "a system of accreditation in professional architecture education that is responsive to the needs of society and allows institutions with varying resources and circumstances to evolve according to their individual needs." https://www.naab. org/info/mission/
4. The National Council of Architectural Registration Boards has, for many years, advocated protecting "public health, safety, and welfare by leading the regulation of the practice of architecture through the development and application of standards for licensure and credentialing of architects." The nonprofit organization, made up of the architectural licensing boards of 54 states and territories, annually provides statistical demographic information on licensure and licensure candidates. https://www.ncarb.org/about/ncarbs-role

\section{INTRODUCTION}

Diversity, equity, and inclusion have been legitimate concerns for both the Architecture profession and architectural education for quite some time, in a variety of ways. Widely acknowledged are the disproportionate numbers of women in the profession in comparison to the numbers seen enrolled in schools of architecture. Equally noted is the extremely low number of minorities in both schools of architecture and the profession.

According to the Bureau of Labor Statistics, less than $29 \%$ of people workings as architects and architectural interns are women, and $23 \%$ are racial minorities or persons of color. ${ }^{1}$ Indeed, schools of architecture are much better in this regard, with the National Center for Educational Statistics providing demographical numbers closer to those found within the U.S. population, though not by much; in $201343 \%$ of enrolled architecture students were women and less than $39 \%$ were persons of color. ${ }^{2}$ Across professional organizations, initiatives are being launched to address the numerical disparities; ones that identify lack of awareness, economic disparity, and the ways firms and schools of architecture are exclusory to women and minorities, whether it be through culture or curriculum as culprits for the low numbers. The ACSA sponsored Equity and Access Survey Reports and Equity in Architecture Surveys bring to light legitimate issues on diversity, equity, and inclusion within both the architectural profession and academia. ${ }^{3}$ Concerns include the disparity between numbers of women staying in the profession in comparison with the much larger numbers of those in school and the extremely low number of minorities admitted and retained in both academia and the profession. NCARB address these issues with professional workshops on equity and inclusion, most recently at their 2018 Annual Business Meeting, including leading professionals in this necessary discourse. These initiatives, although they are effective in terms of increasing 
awareness and dialogue about the deficits, do little in the way of targeted change of the culture which created the need for them. They root themselves far too much in data and do not yet get to the heart of the matter of how both culture and curriculum make firms and schools of architecture exclusory to women and minorities.

The profession's disparity issues are not just representational and it would be disingenuous to operate as if the profession's diversity and equity issues begin and end with disproportionate numbers. There should be investigations into whether these unfortunate disparities are paralleled by disparities in terms of teaching about diversity and equity within schools of architecture, and how this may be contributing to disparities within the built environment. According to information reported on Study Architecture, which is sponsored by the Association of Collegiate Schools of Architecture, only 21 percent of NAAB accredited schools of architecture offer program or course descriptions that specifically address diversity and equity. Moreover, the information reported does not elaborate on whether these schools address or allow for discourse on how architects have contributed to or neglected diversity and equity in the built environment historically, intentionally or unintentionally. The information reported suggests that pedagogical approaches to teaching diversity and equity in academia are varied in focus, circumstantial, and unfortunately do not offer insights into how these schools incorporate this coursework into curricula. The serious deficits we see in society in terms of accessibility and inclusion, both physical and social, should be studied and understood according to new perspectives and shared values, or there exists the risk of educating a new architecture workforce that repeats the mistakes of the past. In his essay Critical Architecture, Between Culture and Form, Hays asserts "...as a functional support for human institutions and as a reification of a collective volition, architecture ennobles the culture that produces it; architecture reconfirms the hegemony of culture and helps to assure its continuity." He then goes on to say, "Misunderstanding is presumed to arise naturally because of the changes in architecture, language, and worldview that have taken place in the time separating the architectural object from the interpreter; the meaning must, therefore, be recovered by a disciplined reconstruction of the cultural situation in which the object originated." ${ }^{4}$ The built environment is a lived experience and architecture is the stage upon which everyday social, political, religious, and cultural issues are performed. Moreover, societies are becoming more global in their economic and cultural reaches and, as such, architects are increasingly stepping into new and more widespread systems of practice. Questions concerning the preservation of cultural identity will undoubtedly be raised in this awakening of wide-spread global practice and culture. These questions are already begin raised in regards to ethnic and cultural population changes due to ideological, political, and economic pulses across the globe.
The re-visiting and reinterpretation of the architectural object being a cornerstone of architectural education, it is not outside the purview of architectural educators to encourage retrospective re-understanding of the disparities found in the built environment. Additionally, as the profession faces changing its practice methods to accommodate a more diverse workforce, it may inadvertently alienate the existing workforce, which is already being outmoded and marginalized in the wake of swift leaps in technology, project deliverance, and material innovations. A retrospective review of architectural history, practice, and education, through a framework of diversity and inclusion, can provide a foundation for a coherent understanding of the built environment in relation to the increasingly global world. This review must be exploratory, integrated, and tactile in its goal of connecting people to place, societal issues to the built, and architecture to behaviors. For architecture students, a deeper, more nuanced understanding of everyday societal crossings and intersections with built form is consequential; for they will be the purveyors of a built environment that supports an everdiversifying population.

Higher education has unique academic freedom and the critical mass and diversity of skills to develop new ideas, to comment on society and its challenges, and to engage in bold experimentation in sustainable living.

-Anthony D. Cortese, "The Critical Role of Higher Education in Creating a Sustainable Future." ${ }^{5}$

\section{THE COURSE'S EXIGENCY}

Driving the need for a new course that retrospectively and introspectively examines our built environment are several inconvenient truths which define the radical changes we will deal with in the built environment. While issues of environmental pollution and climate change have wavered at the forefront of professional concerns, especially as it pertains to how buildings contribute to the problem, broad sweeping changes that affect the profession are also taking place socially, politically and culturally. In many ways, these are not merely changes, but growths that will elucidate just how deficient our current built environment is at addressing the desiderata of our societies. The population growths seen worldwide will undoubtedly affect future architects, as will the vast changes in health outcomes and, consequently, life expectancy. Historical review will reveal the copious ways in which global conflict has affected architectural practice and shaped cities around the world. It is inevitable that current conflicts will do the same, this time in ways unforeseen. The built environment has obvious effects on the natural one, begetting changes in how we interact with it, produce from it and how it functions. Communication methods are now so plentiful that issues a world away find advocacy in any place that can receive an internet connection. Architectural space is indelibly intertwined with social, political and 


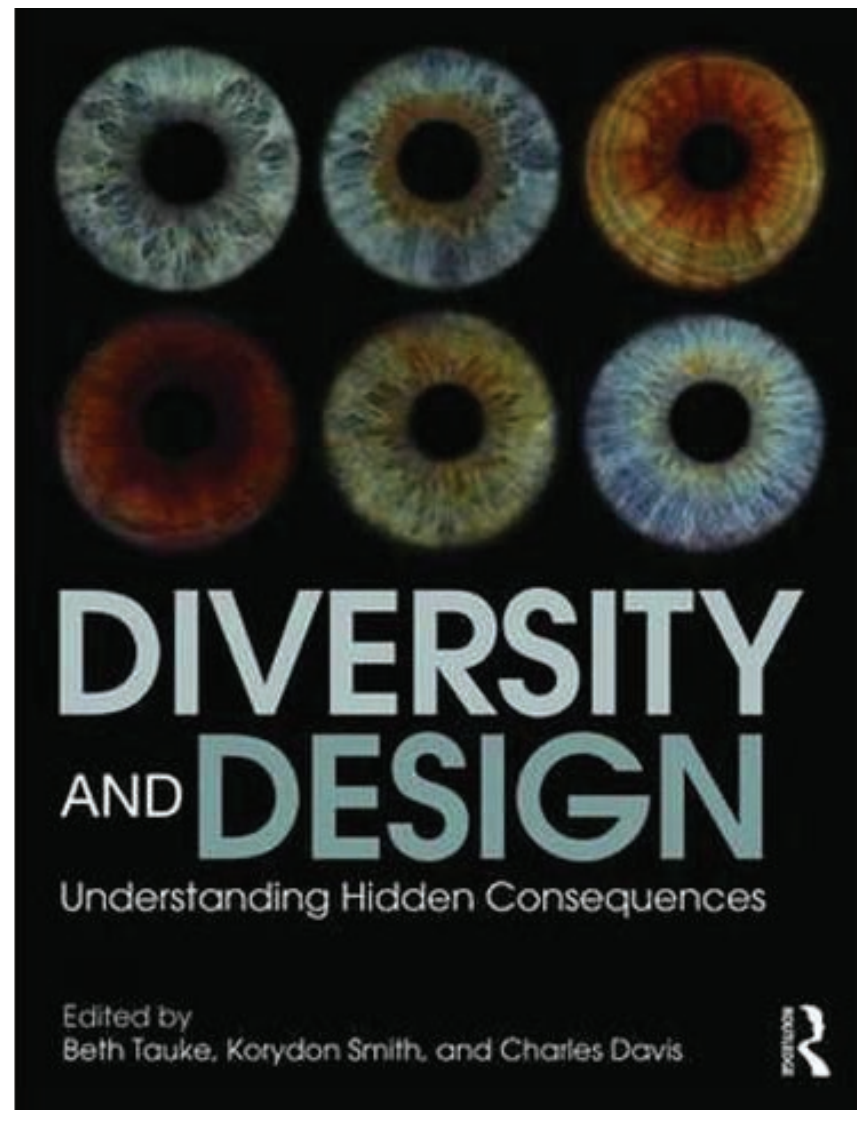

Figure 1. Required text for the Course, Copyright Routledge.

cultural space, charged with the values of the society they are within and fundamentally linked with economies they are outside of. New accessibilities are been discovered to these spaces without older ones having been fixed or established. Architectural space is intricately linked with societal condition, to such a level that societal values can be ascertained completely through the study of built space and how a people move through it.

These new crossings and concerns will inevitably affect architects and the way that they practice. Understandings about the ways in which these considerations will come about is becoming a necessity that must be addressed and schools of architecture are an ideal place to begin cultivating these understandings. The reasons for this are numerous however there are some that are more poignant than others. As stated by Anthony Cortese, "Higher education has unique academic freedom and the critical mass and diversity of skills to develop new ideas, to comment on society and its challenges, and to engage in bold experimentation in sustainable living. ${ }^{5}$ Schools of Architecture are among the most diverse architectural working environments in the world, which make them great places for exploring these topics and also offers a more diverse pool of opinions for exploration of the issues. Additionally, architecture students are also exposed to scholarly travel opportunities at a higher rate than professionals, allowing them to engage the built environment more often and through a markedly more educational lens. Concurrently, schools are architecture, despite having studio environments that are unconventional in comparison to other courses, are ultimately still within institutions of higher education, which are geared towards research, scholarly discussion and conducive to cross-disciplinary research. This setting offers opportunities for engagement, research, and discussion that is free from the time-value restriction of the profession, with a higher chance for those opportunities including a diverse grouping of individuals, possibly with recent educational travel experiences that can inform discussions. At the forefront of the need for the course is the acknowledgment that neutrality in terms of architecture and spatial definition is nonexistent. In the 1988 Atlantic Monthly, former president of France, Francois Mitterrand states "...an epoch is inscribed in it monuments [so] architecture is not neutral[;]... it expresses political, social, economic and cultural "finalities'.

\section{THE COURSE: DIVERSITY AND EQUITY IN DESIGN}

The course, Diversity and Equity in Design, seeks to invigorate the investigative spirit necessary for complex scrutiny of how the built environment intersects with societal statuses, as impetus for compassionate and inclusive design. These intersections are explored at a variety of scales, considering the often multilayered effects of societal deficiency and how architecture, and likely practice, may diminishes or aide in those deficiencies. The course is carried along by the nature of query, research, and discussion, as they are no incorrect propositions nor are there any goals for elucidation of the issues presented. The course invites the pursuit of knowledge for the sake of touting the benefits of extensive consideration, which hopefully leads to a larger understanding of the power of architectural space and ultimately, more empathetic design. In the book Discussion as a way of teaching, the benefits of discussion to classroom learning objectives are listed, citing an "increase in students' awareness of and tolerance for ambiguity," the "development of synthesis and integration skills," and "increasing breath and empathy." The ultimate objective of the course is for students to gain an understanding of the concept of Universal Design, learn about the spatial context of various social issues and explore the effects of globalization on the built environment. Due to the broad nature of the topics explored, the course is divided into four units which allow potential topics to fall under general banners of exploration. Like the course description suggests, however, there is crossover within the topics that leads to the obvious conclusion that the built environment is complex because of the numerous forces acting within and upon it. The role of the architect is discussed in relation to each topic. The responsibility of the architect is scrutinized for connections to actual issues caused by the built. The professional and personal ethics of designers are called into question as a method for revealing how difficult it is to draw lines for professional engagement that truly addresses the safety and welfare of the public. 


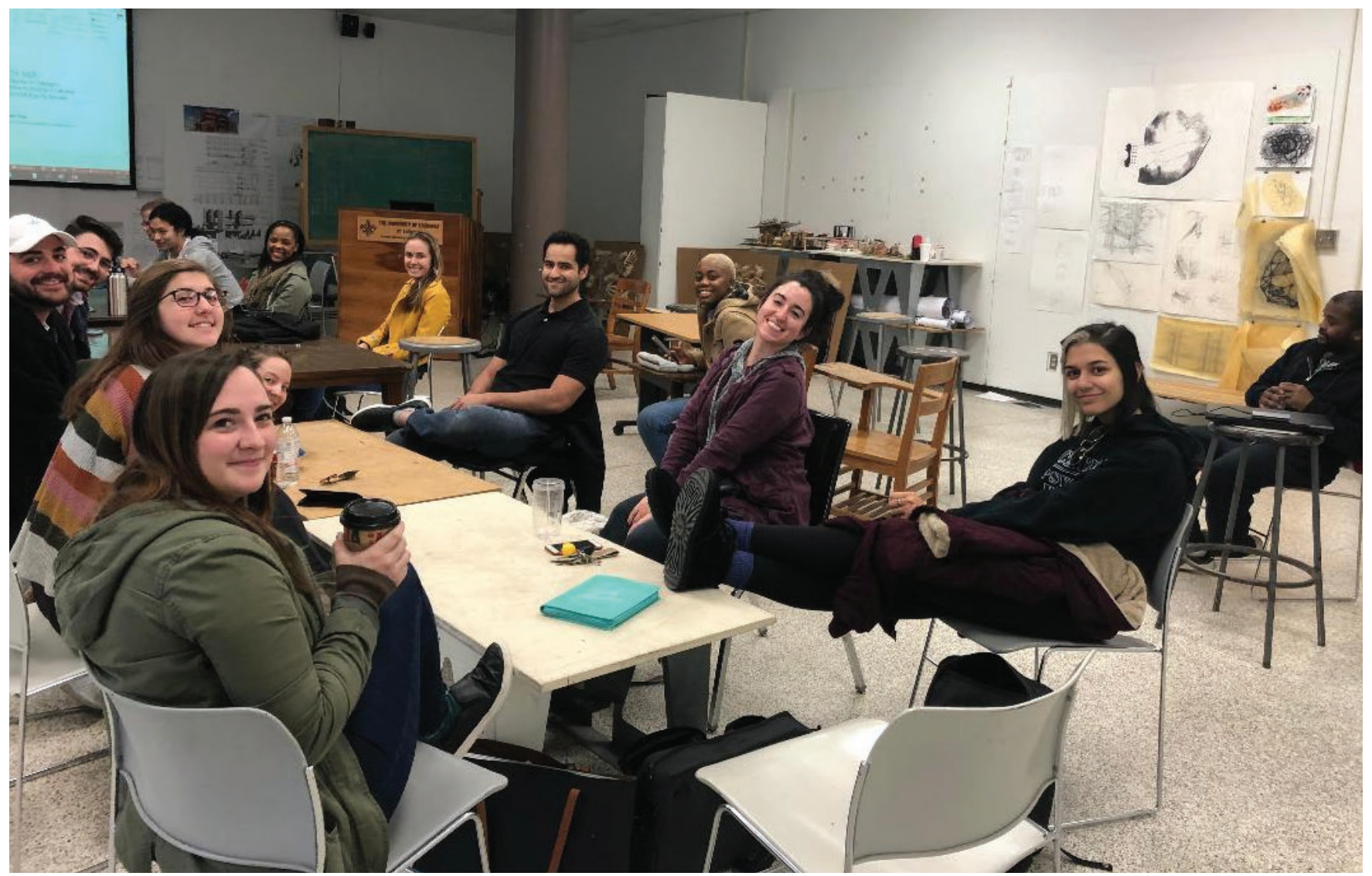

Figure 2. Students engaging in discussion., copyright Kiwana McClung 2019.

Heavily discussed are human conditions in which special consideration and/or accommodations are required during the design process to best serve the needs of the public. The design of facilities for the elderly, for Alzheimer's patients, for the visually impaired, for those with hearing impairments, those with physical disabilities and many more require aforethought that begets spatial conditions conducive to the patron's health, safety, and welfare. Barriers to spaces and structures, or environmental resistance so-to-speak, is examined in an effort to widen understandings of accessibility. Too often, accessibility is presented in terms of minimum standards for the most impaired cases, rather than as the promotion of "...human performance, health and wellness, and social participation...." Some of the more dynamic discussions in the course engaged ideas of professional values and ethics. In one particular class session, there was a frank discussion which concerned one of the readings from one of the required textbooks, Diversity and Design: Understanding Hidden Consequences. The essay titled Architects at War by Lynne Horiuchi outlines a curious case in which architects during World War II were tasked with designing an internment camp that would incarcerate two of their former colleagues, whom were practicing Japanese American Architects prior to the Pearl Harbor attack. ${ }^{9}$ The discussion centered on the clash between personal values and professional ethics, while also bringing to light the ongoing struggles with engaging in discourse concerning racial identity and architectural practice.
Additionally discussed within the course are phenomena that arise due to the effects of globalization. There now exists modes of practice that embrace global culture and firms that have expanded their practices in ways that allow for a more global, corporate methods of project design and delivery. Many critics have argued that this mode of practice has led to a condition in which cities become more alike, minimizing traditional and culturally driven architectural styles and materiality. Leslie Sklair posits that the iconic architecture and megaprojects being constructed in city centers around the world are representative of the "transnational capitalist class," with corporate architecture firms, Starchitects and Signature Architects playing a role in the marketing. ${ }^{9}$ The class discussions on these topics were structured as to not highlight these happenings as right or wrong; it merely asks the question of what happens to ideas of cultural identity through aesthetics, and ideas of place, when global styles becomes commonplace. Several other topics are explored and discussed during the course that reveal just how connected the practice of architecture is to socio-cultural issues that occur within the built environment. These topics include the exploration of spatial issues that arise due to global conflict, the shifting/changing use of architectural spaces/structures, the anthropological, geological and historical issues which affect architecture and architectural practice, and the urban, suburban, and rural issues which affect building and settlement patterns, as well as architectural styles. 


\section{INTERSECTIONS IN PUBLIC \& PR OTE CTED SPACES/STRUCTURES}

Friendship Park

Tijuana, Mexico \& San Diega, CA, 197

"May there n everbea wall between these two greatnations, onk friendsh ip."

-Pat Nixon

\section{HISTORICAL BACKGROUND-IVINIGRATION}

Out af the 41.3 million individuds of foreign birth, $28 \%$ are Nexican making Mexicans the largest group of foreign-bom residents in the country.

Af ter the annexation of Texas in 1845 immigration was low and was met without intemuption for quite same time. In the 1890's, industries in the Southwest attros ted Mexican migrant workers and the Nexican Revolution increased the number of refugees and political exiles fleeing to the United States.

In the 1910's there were chout 20,000 migrants a year compared to 50,000 to 100,000 migrants a year in the 1920 's. For a while Nexicon immigrants did not face the same discrimination as other immigrants from Eastem Eurcoe cnd Asia because they were seen as "better" lchorers and were thought to be cocile, physically strong, and akle to tolerate unhealthy and demanding work conditions. But most importantly they were seen as temporary migrants who were likely to retum to Nexico.

With the mmigration Act of 1924 Mexico as well as all the other coun tries in the Wuestem herrisphere vere exempt from the quotas places on other coun tries due to the agricultural labby that argued they would be unable to fined laborers to work the flelds.

But with the Depression hit in 1929 and industries dried up. the need for immigrants decreased ond thousands af Mexican laborers went back to Vexico. Hundreds of thousands a Mexicans mere also deported under und ficial policies led by federd, municipal or city quthorities.

1924 the Us Border Patrol was created mainly to prohibit Chinese immigrants but it has not remained that way. Nowu Nexico has a quota for immigron ts coming into the Unites States.

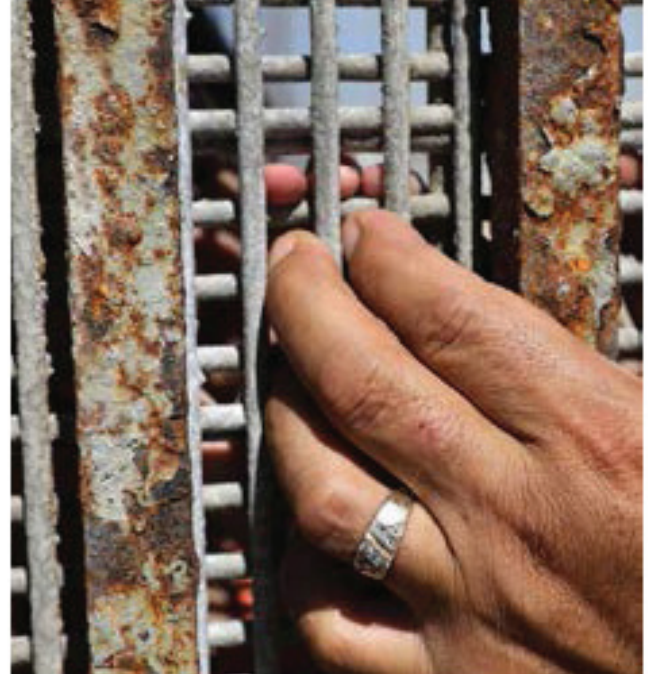

\section{RELEVANCE FOR ARCHITECTS}

The idea behind Friendship Park shouns that the artiflcial boundaries created by govEnments should not prohibit the connestion between pecole. The concept at the park, a place for citizens of two countries to meet and socialize, should be apolied when designing border crossings. These should be treated $c t$ pace of gathering and should not be overshadowed by irational hysteria. They are gate. ways to different countries and should not lock lkefortresses.
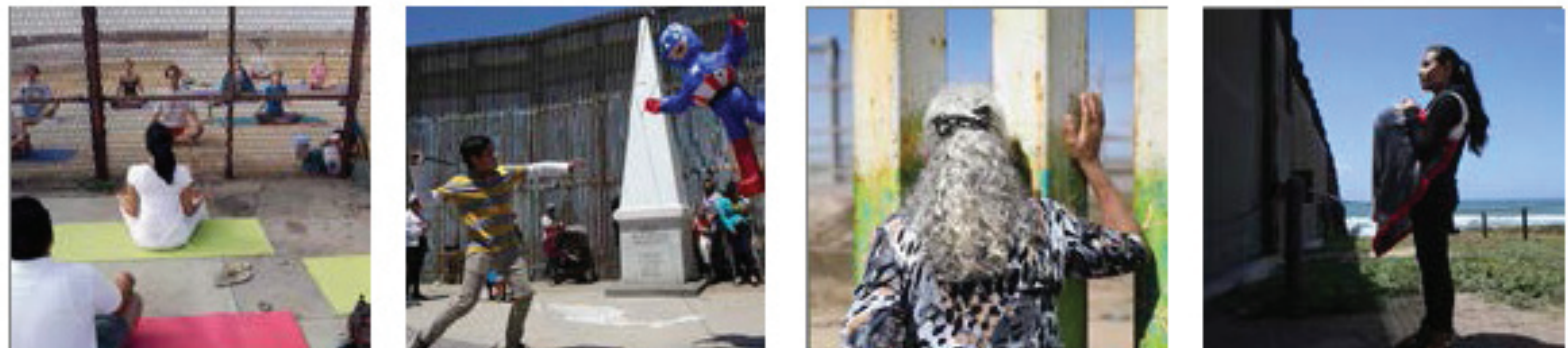

Figure 3. Student Case Study from the course. 


\section{THE COURSE: DIVERSITY AND EQUITY IN DESIGN}

The course is divided into four units that broadly introduce an aspect of society for architectural consideration in terms of planning and practice. Even so, not all aspects of these units can be addressed in one semester, therefore a general lecture is given at the start of each unit to introduce possible topics to the class and then specific topics are chosen for further consideration. The topics chosen for extensive consideration are usually carried by multiple weekly readings from various sources, including by not limited to the required course textbooks. Students are charged with responding to each reading prior to class so that discussion points were already considered and pre-written. Guest speakers from across disciplines are invited in to speak on relevant topics whenever possible. Each unit concludes with individual students conducting and presenting a case-study of a structure or space that is related in some manner to the topics presented in that unit. The course begins with an introduction to diversity and equity in design, outlining the definitions that define the course and establishing just how those words are meant to be interpreted in the course. Diversity for the sake of the course is defined as both a great range of opinion and the quality or fact of including a great range of different people or things. ${ }^{10}$ Equity is defined as employing systems of natural justice, usually not covered by existing laws, in which everyone is considered and treated equally. ${ }^{11}$ The required text for the course is a book titled Diversity and Design: Understanding Hidden Consequences, edited by Beth Tauke, Korydon Smith, and Charles Davis. The text contains a collection of fifteen essay which explore the profound and invisible ways that design affects diverse populations. ${ }^{8} \mathrm{~A}$ second book titled Universal Design: Creating Inclusive Environments, written by Edward Steinfeld and Jordana L. Maisel was also used in the course and focuses on the promotion of accessibility, particularly as it relates to the reduction of barriers, both real and metaphorical. ${ }^{7}$

Unit one focuses on public health and safety, and physical and mental disability considerations. An intro to public health/safety, the aging, and ADA implications, followed by a discourse on ADAAG goals and considerations in the proceeding session allows students the opportunity to discuss a wide range of issues and their implications for the future of design. Broadly discussed in this unit are the realities of our aging populations. According to a report produced by the U.C. Department of Housing and Urban Development, by 2050 the population aged 65 and over is projected to be 83.7 million, almost double what it is today; students examined and the discussed the spatial implications of such a radical change in the aging population. ${ }^{12}$ Unit two focuses on urban, suburban, rural, religious, identity and gender, and race-ethnicity related spatial issues. An intro into this unit is followed by readings and discussions about religious spaces/structures, historical factors that shaped suburban neighborhoods worldwide and the effects of the LGBTQ restroom issues on the profession. Especially referenced in these first two units were the writings of Juhani Pallasmaa, Eyes of the Skin being the most relevant. A quote by Pallasmaa illustrates the goals of the course; "A profound design process eventually makes the patron, the architect, and every occasional visitor in the building a slightly better human being. ${ }^{\prime 13}$

Unit three focuses on the intersections concerning public and protected spaces and structures. Discussions centered on issues with designing in the public realm, design within ecological, historical \& protected Spaces, the idea versus the realities of borders, cultural dichotomies in public spaces, transit-oriented development design, environmental problems, sub-cultural spaces, and heterotopias. One of the more provocative discussions centers on the Tragedy of the Commons by Garrett Hardin and privately-owned/managed public spaces. ${ }^{14}$ These discussions wrestle with the roles architects would play in these charged situations, challenging students to think about what position they would take. Unit four focuses on international spatial ideas, global cultural phenomena, and conflicting social traditions. Topics explored in this unit were the architectural/spatial implications of globalization, rapid urbanization, over-urbanization, spatial conflicts with cultural customs, non-western religious spatial use, and designing for global environmental. Readings from The Icon Project and other works were discussed to identify the relationship between architecture, architectural practice, and global culture. There was obvious overlap between other topics when discussing how cultural customs and events dictate the use of architectural and public space.

As an additional requirement for the course, students are charged with completing a design proposal for a unit which adhered to the ADA Guidelines; specifically one concerned with minimizing falls, which according to the Centers for Disease Control and Prevention was the number one cause of injury and injury-related deaths among adults 65 years of age and older. ${ }^{15}$ The course concludes with each student writing a 2500 word paper on a topic of their choice. Topic choices are heavily vetted by the class and paper topics are presented at the end of the semester so that all students could benefit from this new or previously unknown knowledge.

\section{COURSE OUTCOME AND CONCLUSIONS}

The outcome of the course was highly encouraging in terms of the goals and objectives of the course. Students were engaged throughout the duration of the course and presented case studies which highlighted issues that were particularly important to them. Many of the students in the course were, at the time, developing a thesis for their final graduate projects and communicated that the course helped them better define their architectural positions and interests. Several of the students admitted that they had never considered the hidden consequences of their design moves and were glad to have to have been enlightened. Expected was the marked 
improvement in discussion skills that was witnessed throughout the semester. An unintended consequence of the course was the improvement in writing among the enrolled students. The almost daily process of reading, writing and speaking that was needed to fully engage the course had a profound effect on the intellectual agility of the enrolled students. Students more easily communicated their ideas and were less apprehensive about discussing difficult topics. One student provided feedback via student course evaluation that called for even greater participation in terms of discussion. "The readings provide unique insights. How could involvement [in discussions] be improved?" Overall, the course unfolded as a collaborative learning environment that established the need for empathy, compassion and extensive consideration during the design process. More broadly, the course revealed an alternative way of approaching the discipline, one that relies on diverse perspectives, cross-disciplinary evaluation, and the development of emotional intelligence. The term emotional intelligence, coined by Daniel Goldman, concerns the possibility that a set of abilities, a new form of intelligence pertaining to emotions, which includes the understanding, regulation, and perception of emotions is related to the ability to facilitate and high performance among organization members. ${ }^{16}$ The students often related to the topics of the course in personal ways and emotional responses were respected. Student's understanding, from the beginning of the course, that the topics presented may lead to emotionally charged discussions allowed for empathy to occur first among the students themselves, which then allowed it to be carried over to the people the topics affected directly. The overall conclusion is that courses which embrace diversity and equity issues in the built environment can become extremely vital to a well-rounded architectural education. Student evaluations of the course were overwhelmingly positive, with one student summing up the course by saying "Overall the course is a great addition to the curriculum."

\section{ENDNOTES}

1 "Occupational Outlook on Architects," Bureau of Labor Statistics, U.S. Department of Labor official website, accessed March 2018.

2 "Degrees in Architecture," National Center for Educational Statistics, U.S. Department of Education official website, accessed March 2018.

3 "Where Are the Women? Measuring Progress on Gender in Architecture," The Association of Collegiate Schools of Architecture official website, October 2014. https://www.acsa-arch.org/resources/data-resources/ where-are-the-women-measuring-progress-on-gender-in-architecture/.

4 Michael K. Hays, "Critical Architecture: Between Culture and Form," Perspecta 21 (1984): 14-29. http://www.jstor.org/stable/1567078.

5 Anthony D. Cortese, "The Critical Role of Higher Education in Creating a Sustainable Future," Planning for Higher Education (2003).

6 Stephen D. Brookfield and Stephen Preskill, Discussion as a Way of Teaching: Tools and Techniques for Democratic Classrooms (San Francisco: Jossey-Bass, 2005).

7 Edward Steinfeld and Jordana L. Maisel, Universal Design, Creating Inclusive Environments (Hoboken, NJ: John Wiley \& Sons. Inc., 2012).

8 Beth Tauke, Korydon Smith, and Charles Davis, Diversity and Design: Understanding Hidden Consequences (New York: Routledge, 2016).

9 Leslie Sklair, The Icon Project: Architecture, Cities and Capitalist Globalization (New York: Oxford University Press, 2017).
10 Oxford Learner's Dictionary, "Diversity" noun entry, accessed October 1, 2017. https://www.oxfordlearnersdictionaries.com/us/definition/english/ diversity?q=diversity

11 Oxford Learner's Dictionary, "Equity" noun entry, accessed October 1 2017. https://www.oxfordlearnersdictionaries.com/us/definition/english/ equity_1?q=equity.

12 "Preventing Falls By The Elderly Final Report," Contract \#DU203NP-15-D-06, Order \#004, Office of Lead Hazard Control and Healthy Homes, U.S. Department of Housing and Urban Development official website, February 2017.

13 Juhani Pallasmaa, The Eyes of the Skin: Architecture and the Senses (Chichester, England: Wiley, 2014).

14 Garrett Hardin, "The Tragedy of the Commons," Science 162, no. 3859 (December 1968): 1243-1248. https://science.sciencemag.org/ content/162/3859/1243

15 "Home and Recreational Safety," Centers for Disease Control and Prevention official website, August 19, 2016. https://www.cdc.gov/homeandrecreationalsafety/falls/fallcost.html.

16 Stéphane Côté and Christopher T. H. Miners, "Emotional Intelligence, Cognitive Intelligence, and Job Performance," Administrative Science Quarterly 51, no. 1 (March 2006): 1-28. http://journals.sagepub.com/doi/abs/10.2189/asqu.51.1.1.

\section{REFERENCES AND RESOURCES}

"2014 Conditions for Accreditation." Washington, D.C.: The National Architectural Accrediting Board, Inc. 2014.

"A Guide to the 2014 Conditions for Accreditation and Preparation of an Architecture Program Report." Washington, D.C.: The National Architectural Accrediting Board, Inc. 2014.

"Diversity and Inclusion - Diversity Within the AIA." The American Institute of Architects. 2011. http://www.aia.org/about/initiatives/AIAS076703.

"Diversity within the Profession of Architecture: Executive Summary 2016." Executive Summary, Shugoll Research. Washington, D.C.: The American Institute of Architects. 2016. http://aiad8.prod.acquia-sites.com/sites/default/files/2016-05/ Diversity-DiversityinArchitecture.pdf.

"Equity, Diversity, and Inclusion: Resources." Accessed March 2018.

"Equity in Architecture Survey." Survey Findings. AIA San Francisco Equity by Design Committee. 2014.

Evans, Gary W. "The Built Environment and Mental Health." Journal of Urban Health: Bulletin of the New York Academy of Medicine 80, no. 4 (2003): 536.

Kaur, Baljit. "Equity and Social Justice in Teaching and Teacher Education." Teaching and Teacher Education: An International Journal of Research and Studies 28 (2012): 485-492

Milem, Jeffrey. The Educational Benefits of Diversity: Evidence from Multiple Sectors. 2008. PDF.

“NCARB By The Numbers Report." Washington, D.C.: The National Council of Architectural Registration Boards. 2018.

Wells, Nancy M., Gary W. Evans, and Yizhao Yang. "Environments and Health: Public Planning Decisions as Public Health Decisions." Journal of Architectural and Planning Research 27, no. 2 (2010): 124-143. 